\title{
USO DO MAPA DE SOLOS COMO SUBSÍDIO PARA DEFINIÇÃO DE ÁREAS DE SUSCETIBILIDADE À EROSÃO NA BACIA HIDROGRÁFICA SÃO JOÃO, LAGOS E UNA
}

\author{
USE THE MAP OF SOIL AS SUBSIDY FOR DEFINING AREAS ON EROSION SUSCEPTIBILITY TO BASIN SÃO \\ JOÃO, LAGOS AND UNA
}

\author{
Vanessa Ingrid Carvalho Saraiva ${ }^{1}$, Antonio Soares da Silva ${ }^{1}$, Jefferson Pereira Caldas dos Santos ${ }^{2}$ \\ ${ }^{1}$ Universidade do Estado do Rio de Janeiro (UERJ), Rio de Janeiro, RJ, Brasil \\ ${ }^{2}$ Fundação Oswaldo Cruz (Fiocruz), Rio de Janeiro, RJ, Brasil
}

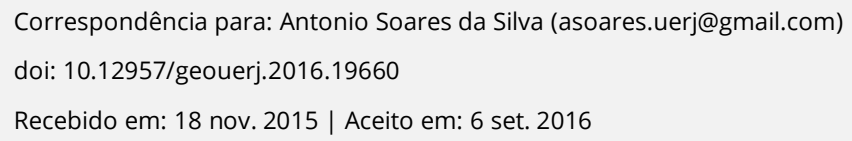

\section{RESUMO}

A bacia hidrográfica do rio São João, Una e Lagos apresenta fortes contrastes pedológicos, geomorfológicos e climáticos. Esta variação cria condições para que espacialmente os solos respondam de forma diferenciada às ações a são submetidos. Esta bacia também foi alvo de ações retificação de canais fluviais e abertura de canais de drenagem. Ainda que tenham sido realizados estudos de mapeamento de solos de parte da bacia, nenhum estudo para se obter o conhecimento das fragilidades dos solos foi desenvolvido. O objetivo do presente artigo foi o de complementar o mapa de solos da bacia do rio São João, Una e Lagos para então realizar a análise da suscetibilidade à erosão dos solos da bacia. A metodologia do estudo foi dividida em complementação do mapa de solos e a partir do método Delphis e de ferramentas de geotecnologias definir graus de suscetibilidade à erosão dos solos que variaram de "muito baixa" até "muito alta". O mapa de solos mostra a ampla ocorrência dos Argissolos, que ocupam cerca de $40 \%$ da bacia. O mapa de suscetibilidade à erosão dos solos aponta que a classe muito baixa é a de maior proporção espacial, devido ao relevo pouco íngreme de grande parte da bacia, sendo a segunda maior a classe "alta" onde predominam Argissolos sob uso de pastagem.

Palavras-chave: erosão dos solos; mapa de solos; rio São João; bacia de drenagem; Argissolos.

\begin{abstract}
The hydrographic basin of the river São João, Una and Lagos presents strong pedological, geomorphological and climatic contrasts. This variation creates conditions for soils to, spatially, respond differently to the actions that are submitted. The basin has also undergone rectification of river channels and the opening of drainage canals. Although it has been made soil mapping studies of part of the basin to define the agricultural potential of the land., no study to obtain knowledge of soil fragilities was developed. This article's purpose was to complement the soil map of the basin of river São João, Una and Lagos to then carry out the analysis of susceptibility to erosion of the basin soils. The methodology of the study was divided into complementing the soil map of the region from the Delphis method and, from geotechnology tools, define levels of susceptibility to soil erosion that ranged from "very low" to "very high". The soil map shows the widespread occurrence of Ultisols, which occupy about $40 \%$ of the basin. The map of susceptibility to soil erosion suggests that the very low susceptibility category is the most predominant, if spatially considered, due to the fact that most of the basin reliefs is not too steep. The second most prevailing category is that of high susceptibility where Ultisols predominate as grazing lands.
\end{abstract}

Keywords: soil erosion; soil map; São João river; drainage basin, Ultisols. 


\section{INTRODUÇÃO}

O processo de erosão dos solos representa um dos maiores problemas de degradação ambiental das paisagens (MARTÍN-FERNÁNDEZ e MARTÍNEZ-NÚÑEZ, 2011; JORGE e GUERRA, 2013). Este pode ser entendido como a dinâmica do desprendimento e arraste das partículas do solo (BOARDMAN e POESEN, 2006).

Quando em equilíbrio este processo contribui para a evolução natural dos relevos e solos (VITTE e MELLO, 2007), porém a atividade humana tem gerado um incremento de erosão devido à má utilização dos recursos do solo (SHI et al., 2008). Os padrões de desenvolvimento da erosão são diversos e complexos, os principais fatores de influência são erosividade da chuva, erodibilidade dos solos, topografia, uso e manejo dos solos (GUERRA et al., 2014).

O conhecimento dos tipos e da distribuição dos solos no espaço auxilia no planejamento e uso de seus recursos. A realização de levantamento de solos na escala apropriada é uma importante ferramenta para o planejamento e gestão do uso da terra.

O levantamento de solos consiste na confecção de um mapa onde se encontram representados os elementos gráficos e geográficos de uma unidade de mapeamento. Ele é constituído por um mapa texto explicativo que define, descreve e interpreta, para diversos fins, as classes de solos de uma determinada área (EMBRAPA, 2013).

Um mapa de solos contém informações, tais como, características químicas, topográficas e tipo de uso predominante em cada unidade de mapeamento. Sendo assim, a partir do levantamento de solos tornase possível espacializar as unidades de mapeamento, bem como delimitar áreas de maior ou menor potencial agrícola e níveis de suscetibilidade à erosão (WANG et al., 2009; GUERRA, 2014).

Os dois principais tipos de uso dado aos solos do mundo é a prática agrícola e a pecuária. Bertoni e Lombardi Neto (1990) observam que o uso do solo como pastagem aumenta a perda de partículas do 
mesmo em 100 vezes, quando comparado com as áreas florestadas. Esta perda de solo é potencializada quando a agricultura e a pecuária são praticadas em áreas com relevo ondulado ou montanhoso. Sabese que a topografia é um dos elementos fundamentais no aumento das perdas de solos. Para Rossi e Pfeiffer (1999) o relevo foi o fator mais importante para a remoção de materiais, e na estabilidade do relevo em domínios de colinas e serras, em comparação com outras variáveis, tais como, concavidade e tipo de solo.

A Bacia Hidrográfica do São João, Lagos e Una apresenta como principal uso do solo a pecuária. 0 relevo é caracterizado principalmente por colinas, com declividades acima de $5 \%$ em sua maior parte. Destaca-se ainda as planícies junto ao litoral e as serras no limite norte da bacia.

A bacia hidrográfica é constituída pelas bacias dos rios São João, Una e pela drenagem que deságua no sistema lagunar da Região das Baixadas Litorâneas. Possui uma área de 3.804 km², correspondendo a cerca de 8\% do território do estado do Rio de Janeiro (Figura 1). O Consórcio Intermunicipal Lagos São João, criado em 1999 é o órgão responsável pela gestão desta bacia hidrográfica.

$\mathrm{Na}$ década de 50 foram realizadas uma série de intervenções de engenharia que modificaram o seu padrão de ocupação espacial e sua dinâmica ambiental. O regime fluvial, no âmbito do canal, foi drasticamente alterado após a construção do Reservatório de Juturnaíba e obras de retificação da calha do rio São João (CUNHA, 1995; 2004).

Sob o ponto de vista da circulação atmosférica, a bacia permanece a maior parte do ano, sobre a influência da Massa Tropical Atlântica (MTA), em geral, apresenta temperaturas médias anuais de $18^{\circ} \mathrm{C}$ a $24^{\circ} \mathrm{C}$, com índice de precipitação de $700 \mathrm{~mm}$ até $2400 \mathrm{~mm}$.

Seu relevo varia consideravelmente, na parte leste encontra-se o litoral e mais para seu interior predominam colinas do tipo meia laranja e os vales alargados, na parte oeste encontra-se as encostas dissecadas e, na parte norte, as escarpas da Serra do Mar. 
O uso do solo na bacia hidrográfica do São João, Lagos e Una é heterogêneo, apresentando áreas densamente ocupadas e urbanas como Arraial do Cabo, Cabo Frio, e áreas de ocupação esparsa e atividades rurais associadas como Silva Jardim. Contudo são as pastagens a classe de uso que ocupa a maior área da bacia, estando localizada majoritariamente na porção central da mesma. A região do estudo foi alvo de projetos de desenvolvimento agrícola, pois trata-se de uma das poucas áreas do estado com relevo que favorece à mecanização. Em uma tentativa de viabilizar uma ocupação mais intensa, a EMBRAPA Solos realizou um levantamento de solos em parte da bacia (quadrículas de Silva Jardim e Rio das Ostras), onde se observou o predomínio de Argissolos (LUMBRERAS et al., 2001). No entanto, este mapa priorizou o setor de colinas e de planícies da bacia, não contemplando o setor serrano.

A partir da premissa de que a erosão é um dos mais graves processos de degradação dos solos e que as ações implementadas na bacia objetivam ampliar o uso das terras. Este trabalho tem como objetivo avaliar a suscetibilidade a erosão dos solos da bacia hidrográfica do rio São João, Lagos e Una com base no mapa de solos produzido por Lumbreras et al. (2001) e Carvalho Filho et al. (2003). Para alcançar este objetivo houve a necessidade de complementar o mapa de solos, no setor serrano, de modo a abranger toda a bacia.

Estudos a respeito da suscetibilidade da erosão dos solos, bem como sua disponibilização para os diferentes órgãos gestores ambientais e de planejamento podem potencializar a ação destes junto às áreas degradadas e sensíveis aos processos erosivos. Uma análise da suscetibilidade a erosão na bacia hidrográfica do rio São João, Lagos e Una é importante para que se possa realizar um melhor planejamento do seu uso, visto que a mesma apresenta grandes áreas de Argissolos, solos estes que, em geral, são altamente suscetíveis à erosão (BERTONI e LOMBARDI NETO, 1990; MORGAN, 2005). 


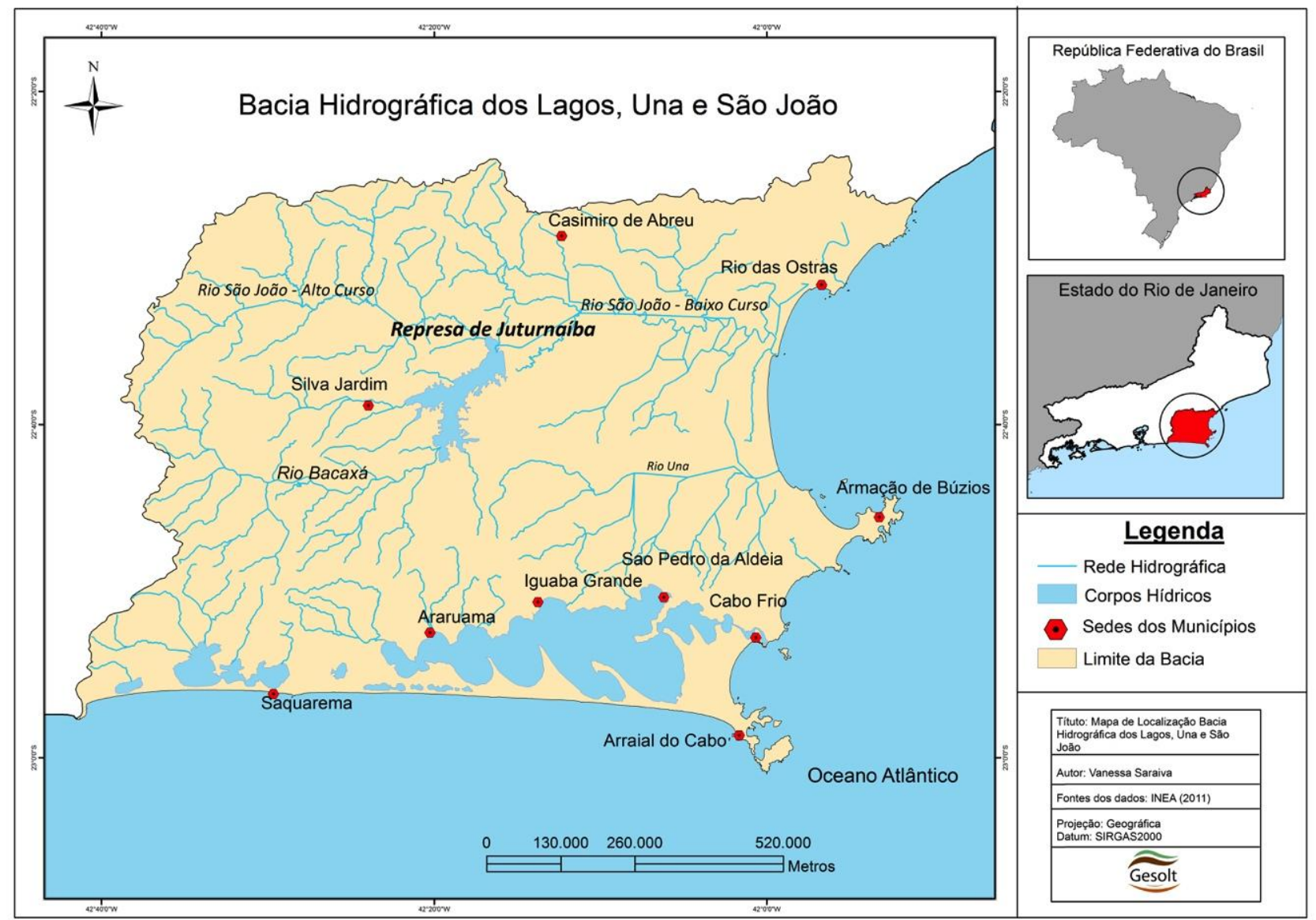

Figura 1. Mapa de Localização da Área de Estudo.

\section{Metodologia}

A primeira fase do trabalho consistiu na compatibilização do Mapa de Reconhecimento de Alta Intensidade dos Solos na escala de 1:100.000 (LUMBRERAS et al., 2001) e da Carta de Reconhecimento de Baixa Intensidade dos Solos do Estado do Rio de Janeiro na escala de 1:250.000 (CARVALHO FILHO et al., 2003). Os mapas foram digitalizados, georreferenciados e vetorizados no software ArcGIS 9.2®.

A partir da digitalização destas informações foi construído um banco de dados geográficos de solos da área de estudo, onde foram incluídos os resultados das análises de perfis de solos descritos por Lumbreras et al. (2001). A estes dados foram somados 18 novos perfis de solos (Figura 2), abertos para complementar as observações feitas por Lumbreras et al. (2001). Nestes perfis, optou-se por realizar a descrição morfológica, diagnóstico de campo e coleta de amostras para granulometria e 
carbono orgânico no Laboratório de Geografia Física (LAGEFIS) da Universidade do Estado do Rio de Janeiro (UERJ). Para estas análises e descrições foram usadas as bases definidas por LEMOS e SANTOS (1996), EMBRAPA (1997) e a carta de cores de MUNSELL (1994).

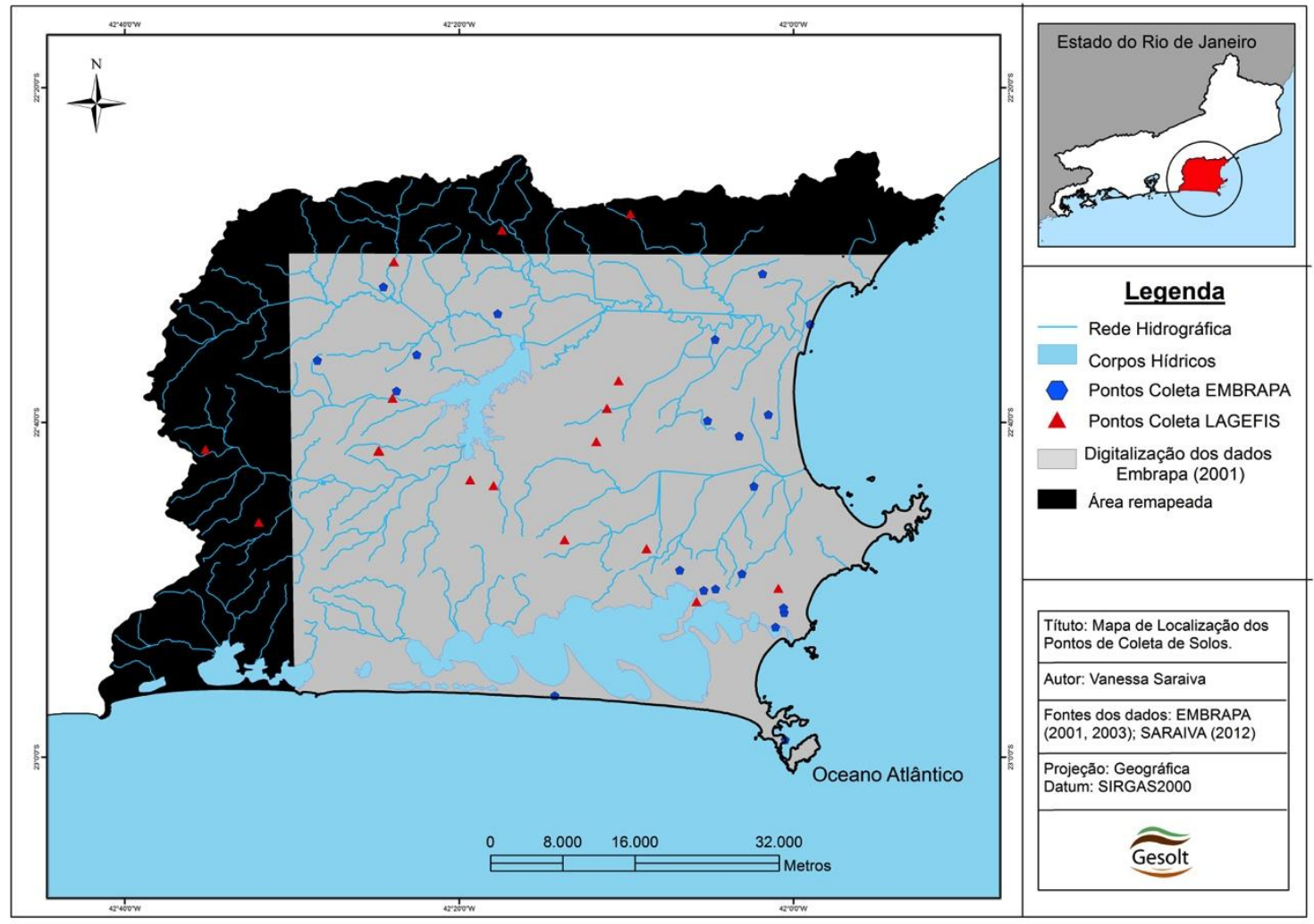

Figura 2. Mapa de localização dos pontos de solo analisados e da área digitalizada e mapeada.

Com o levantamento de solos realizado para a área foi possível identificar as características de cada unidade de mapeamento tais como: profundidade do solo, texturas dos horizontes A e B, gradiente textural, tipo de solo, relevo, declividade e uso e ocupação. Estas características foram as utilizadas na confecção da análise de suscetibilidade a erosão.

As notas das características de cada unidade de mapeamento utilizadas na análise da suscetibilidade à erosão superficial do solo foram obtidas pelo método Delphis. Em linhas gerais, o método se caracteriza pela consulta a especialistas a respeito de um determinado evento através de um questionário, que é repassado continuadas vezes até que se atinja uma comunhão nas respostas, que representa uma consolidação do julgamento intuitivo em grupo. 0 anonimato dos julgamentos é um 
ponto importante do método. Existem diversas variações e adaptações do método para que o mesmo se adeque melhor ao objeto de estudo em questão (ADLER e ZIGLIO, 1996). Diversos estudos utilizaram este método, dentre os quais cita-se as pesquisas sobre erosão costeira (LUO et al., 2013), de mudanças climáticas (BILOSLAVO e GRANBENC, 2012) e de risco ambiental (BRYANT e ABKOWITZ, 2007; MARINO et al., 2012).

O Quadro 1 foi obtido com base nas respostas obtidas no Delphis e resume as principais características notadas para avaliação da erosão. A suscetibilidade a erosão dos solos pode variar de "muito baixa" até "muito alta". Neste quadro é possível observar a gradação tomada para cada variável separadamente, de acordo com o tipo de solo, suas características físicas, tipo de uso e ocupação, relevo e declividade.

Cada associação de solo, a partir da média das notas dadas a cada variável, recebeu uma nota (1 a 5) variando desde muito baixa até muito alta suscetibilidade a erosão seguindo os parâmetros já citados.

\begin{tabular}{|c|c|c|c|c|c|}
\hline Fator do solo & \multicolumn{5}{|c|}{ Classes de suscetibilidade à erosão dos solos } \\
\hline Classes & Muito alta & Alta & Moderada & Baixa & Muito Baixa \\
\hline $\begin{array}{l}\text { Profundidade } \\
\text { do solo }\end{array}$ & $>150 \mathrm{~cm}$ & $100-150 \mathrm{~cm}$ & $50-100 \mathrm{~cm}$ & $50-30 \mathrm{~cm}$ & $<30 \mathrm{~cm}$ \\
\hline $\begin{array}{c}\text { Textura } \\
\text { Horizonte A }\end{array}$ & Arenosa & Média & Média & - & - \\
\hline $\begin{array}{c}\text { Textura } \\
\text { Horizonte B }\end{array}$ & Muito argilosa & Argilosa & Média & Média & Arenosa \\
\hline $\begin{array}{c}\text { Gradiente } \\
\text { textural }\end{array}$ & Abrupto & Forte & Moderado & Ausente & Ausente \\
\hline Tipo de solo & $\begin{array}{l}\text { Argissolos e } \\
\text { Planossolos }\end{array}$ & $\begin{array}{c}\text { Argissolos / } \\
\text { Cambissolos / } \\
\text { Neossolos Litólicos }\end{array}$ & Latossolos & - & $\begin{array}{c}\text { Neossolos } \\
\text { Flúvicos, } \\
\text { Espodossolos } \\
\text { Gleissolos }\end{array}$ \\
\hline Relevo & $\begin{array}{c}\text { Montanhoso/ } \\
\text { Forte Ondulado }\end{array}$ & Colinoso & Suave Colinoso & $\begin{array}{c}\text { Plano / Suave } \\
\text { Ondulado }\end{array}$ & Plano \\
\hline Declividade & $>20 \%$ & $15-20 \%$ & $10-15 \%$ & $5-10 \%$ & até $5 \%$ \\
\hline $\begin{array}{c}\text { Uso e } \\
\text { Ocupação }\end{array}$ & $\begin{array}{c}\text { Pastagem não } \\
\text { manejada }\end{array}$ & $\begin{array}{l}\text { Agricultura com } \\
\text { ou sem manejo }\end{array}$ & Campo sujo & $\begin{array}{c}\text { Áreas de } \\
\text { reflorestamento } \\
\text { e florestas em } \\
\text { estágio inicial }\end{array}$ & $\begin{array}{l}\text { Florestas } \\
\text { densas, } \\
\text { restingas e } \\
\text { mangues }\end{array}$ \\
\hline
\end{tabular}

Quadro 1. Principais varáveis consideradas e suas respectivas classes de suscetibilidade à erosão. Legenda: A ausência de informação em determinadas classes ocorreu na variável textura do horizonte A, que não teve 
valores nas classes baixa e muito baixa, e, tipo de solo, que não teve nenhum solo associado a classe baixa. Estas ausências foram representadas pelo símbolo “_“.

\section{Resultados}

Foram selecionados 9 (nove) perfis de solo para apresentação dos resultados de granulometria. Há um amplo predomínio de Argissolos e Latossolos. Estes solos apresentam textura argilosa e teores de argila ultrapassando $400 \mathrm{~g} \mathrm{kg-1} \mathrm{(Tabela} \mathrm{1).} \mathrm{A} \mathrm{bacia} \mathrm{apresenta} \mathrm{na} \mathrm{transição} \mathrm{entre} \mathrm{as} \mathrm{colinas} \mathrm{e} \mathrm{as}$ planícies solos do tipo Planossolos. Este possui como característica principal um forte contraste textural entre os horizontes A e Btg. Em alguns casos, esta relação pode atingir 2,9, o que confere a estes solos o caráter abrúptico (Lumbreras et al., 2001).

\begin{tabular}{|c|c|c|c|c|c|c|c|}
\hline \multirow[b]{2}{*}{ Tipo de Solo } & \multicolumn{7}{|c|}{ Composição granulométrica g.kg ${ }^{-1}$} \\
\hline & $\underline{\text { Horizonte }}$ & $\underline{\text { Profundidade }}$ & $\frac{\text { Areia }}{\text { Grossa }}$ & $\frac{\text { Areia }}{\text { Fina }}$ & $\underline{\text { Silte }}$ & $\underline{\text { Argila }}$ & $\underline{\mathrm{MO}(\%)}$ \\
\hline \multirow{2}{*}{$\begin{array}{c}\text { Neossolo } \\
\text { Flúvico }\end{array}$} & $\mathrm{A}$ & 1020 & 547 & 319 & 91 & 43 & 1,24 \\
\hline & $\mathrm{C} 4$ & $56-72$ & 850 & 112 & 21 & 17 & 0,7 \\
\hline \multirow{4}{*}{$\begin{array}{l}\text { Latossolo } \\
\text { Amarelo }\end{array}$} & A & $0-10$ & 510 & 65 & 120 & 305 & 3,59 \\
\hline & $\mathrm{AB}$ & 16 & 432 & 79 & 82 & 407 & 2,4 \\
\hline & Bw1 & 65 & 356 & 66 & 57 & 512 & 1,05 \\
\hline & $\mathrm{Bw} 2$ & 100 & 372 & 63 & 56 & 509 & 0,68 \\
\hline \multirow{3}{*}{$\begin{array}{c}\text { Argissolo } \\
\text { Vermelho- } \\
\text { Amarelo }\end{array}$} & $\mathrm{A}$ & $0-10$ & 465 & 96 & 197 & 243 & 2,92 \\
\hline & $\mathrm{Bt}$ & $50-60$ & 309 & 66 & 199 & 426 & 0,5 \\
\hline & $\mathrm{Bt} 2$ & $90-100$ & 29 & 75 & 252 & 383 & 0,27 \\
\hline \multirow{2}{*}{$\begin{array}{c}\text { Argissolo } \\
\text { Vermelho- } \\
\text { Amarelo }\end{array}$} & $\mathrm{A}$ & $0-12$ & 304 & 185 & 281 & 230 & 2,48 \\
\hline & $\mathrm{Bt}$ & $45-55$ & 192 & 99 & 138 & 570 & 0,9 \\
\hline \multirow{5}{*}{$\begin{array}{l}\text { Argissolo } \\
\text { Vermelho- } \\
\text { Amarelo }\end{array}$} & $\mathrm{A}$ & $5,-15$ & 511 & 255 & 149 & 85 & 1,16 \\
\hline & $\mathrm{BA}$ & $24-31$ & 392 & 144 & 106 & 359 & 0,75 \\
\hline & B & $50-60$ & 204 & 59 & 107 & 629 & 0,44 \\
\hline & $\begin{array}{c}\text { L DE } \\
\text { PEDRA }\end{array}$ & - & 221 & 48 & 166 & 565 & 0,44 \\
\hline & $\mathrm{BC} / \mathrm{CB}$ & $100-110$ & 247 & 71 & 172 & 510 & 0,24 \\
\hline \multirow{3}{*}{$\begin{array}{l}\text { Argissolo } \\
\text { Amarelo }\end{array}$} & $\mathrm{A}$ & $5,-15$ & 342 & 140 & 279 & 239 & 2,39 \\
\hline & $\mathrm{BA}$ & $40-50$ & 353 & 115 & 154 & 378 & 0,84 \\
\hline & $\mathrm{Bt}$ & $100-110$ & 197 & 77 & 102 & 625 & 0,28 \\
\hline \multirow{3}{*}{$\begin{array}{c}\text { Gleissolo } \\
\text { Háplico }\end{array}$} & $\mathrm{A}$ & $10,-20$ & 602 & 248 & 101 & 49 & 0,62 \\
\hline & $\mathrm{C} 1$ & $40-50$ & 471 & 239 & 165 & 125 & 0,46 \\
\hline & C3 & $100-110$ & 483 & 395 & 65 & 58 & 0,26 \\
\hline \multirow{2}{*}{$\begin{array}{c}\text { Planossolo } \\
\text { Hidromórfico }\end{array}$} & $\mathrm{A}$ & $0-15$ & 649 & 215 & 88 & 48 & 1,5 \\
\hline & $\mathrm{E}$ & $35-45$ & 665 & 196 & 89 & 51 & 0,63 \\
\hline
\end{tabular}




\begin{tabular}{|cccccccc|}
\hline & $\mathrm{E}$ & $80-90$ & 623 & 217 & 88 & 72 & 0,42 \\
\cline { 2 - 8 } & $\mathrm{Btg}$ & $90+$ & 266 & 93 & 103 & 538 & 0,62 \\
\hline \multirow{2}{*}{$\begin{array}{c}\text { Planossolo } \\
\text { Háplico }\end{array}$} & $\mathrm{A}$ & $0-14$ & 576 & 153 & 112 & 158 & 1,96 \\
\cline { 2 - 8 } & $\mathrm{E}$ & $14-20$ & 510 & 171 & 109 & 209 & 1,16 \\
\cline { 2 - 8 } & $\mathrm{Btg}$ & $45-55$ & 294 & 80 & 97 & 529 & 0,45 \\
\hline
\end{tabular}

Tabela 1. Granulometria e teor de matéria orgânica nas amostras complementares às de Carvalho Filho et al.

(2001).

Os solos Latossolos e Argissolos são predominantemente vermelho-amarelos (Figura 3a), sendo que os primeiros não apresentam contraste textural e os segundos apresentam relação textural sempre superior a 1,7. Por sua vez, os Neossolos Flúvicos e Gleissolos estão associados aos ambientes de deposição de rio São João e demais rios da bacia (Figura 3b).

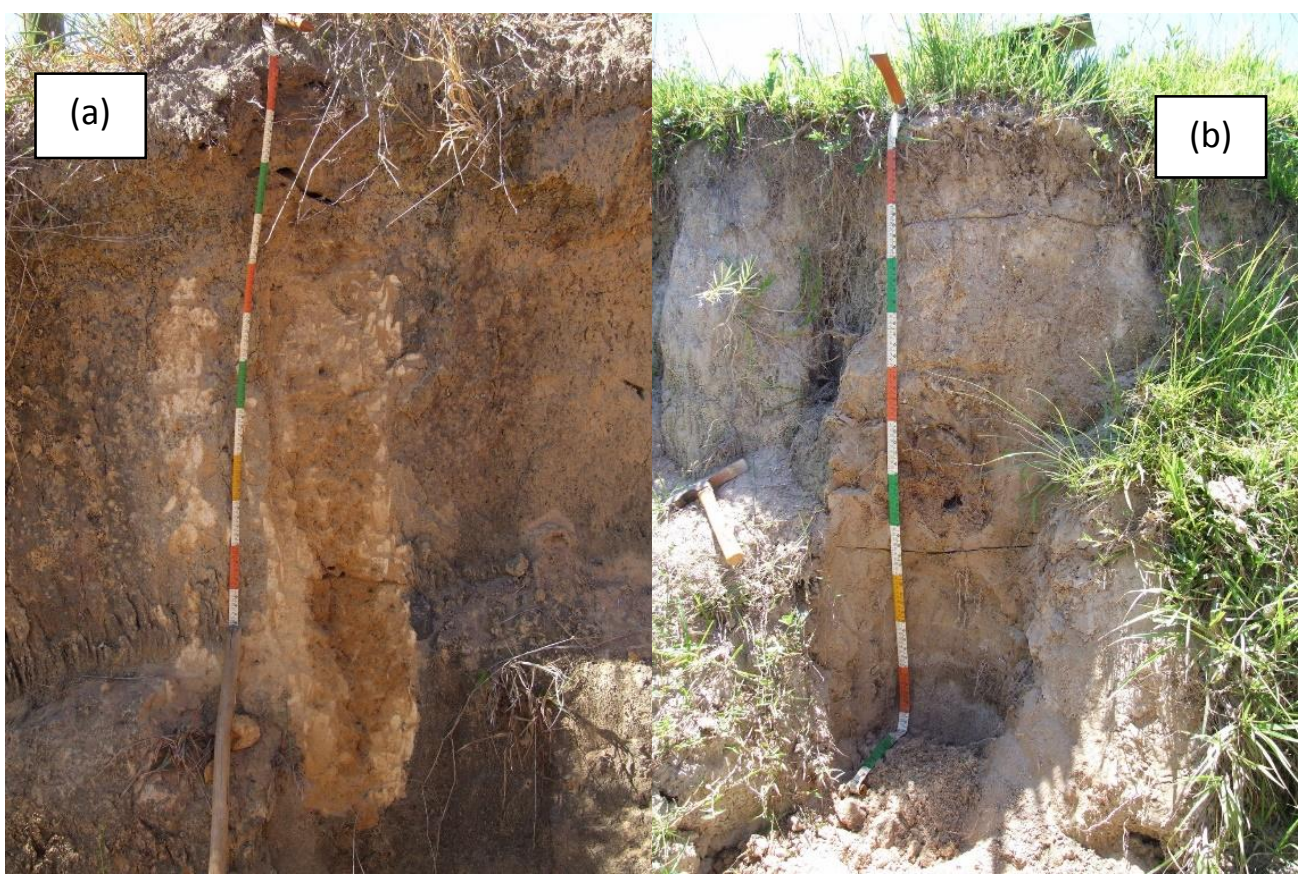

Figura 3. Perfil do Argissolo Amarelo (a); perfil de um Neossolo Flúvico (b). Foto: Antonio Soares da Silva (2012).

\section{Distribuição dos Solos da Bacia dos Lagos - São João}

$\mathrm{Na}$ elaboração do mapa de solos foram criadas novas associações de solos de forma similar às associações de solos de Lumbreras et al. (2001) e Carvalho Filho et al. (2003). 
Na análise do Mapa de Solos nota-se o predomínio das associações de Argissolos (PAd, PVe, PVA), que ocupam uma área de $1.503 \mathrm{~km}^{2}$, representando $42 \%$ de todas as associações mapeadas na área de estudo (Figura 4 e Quadro 2).

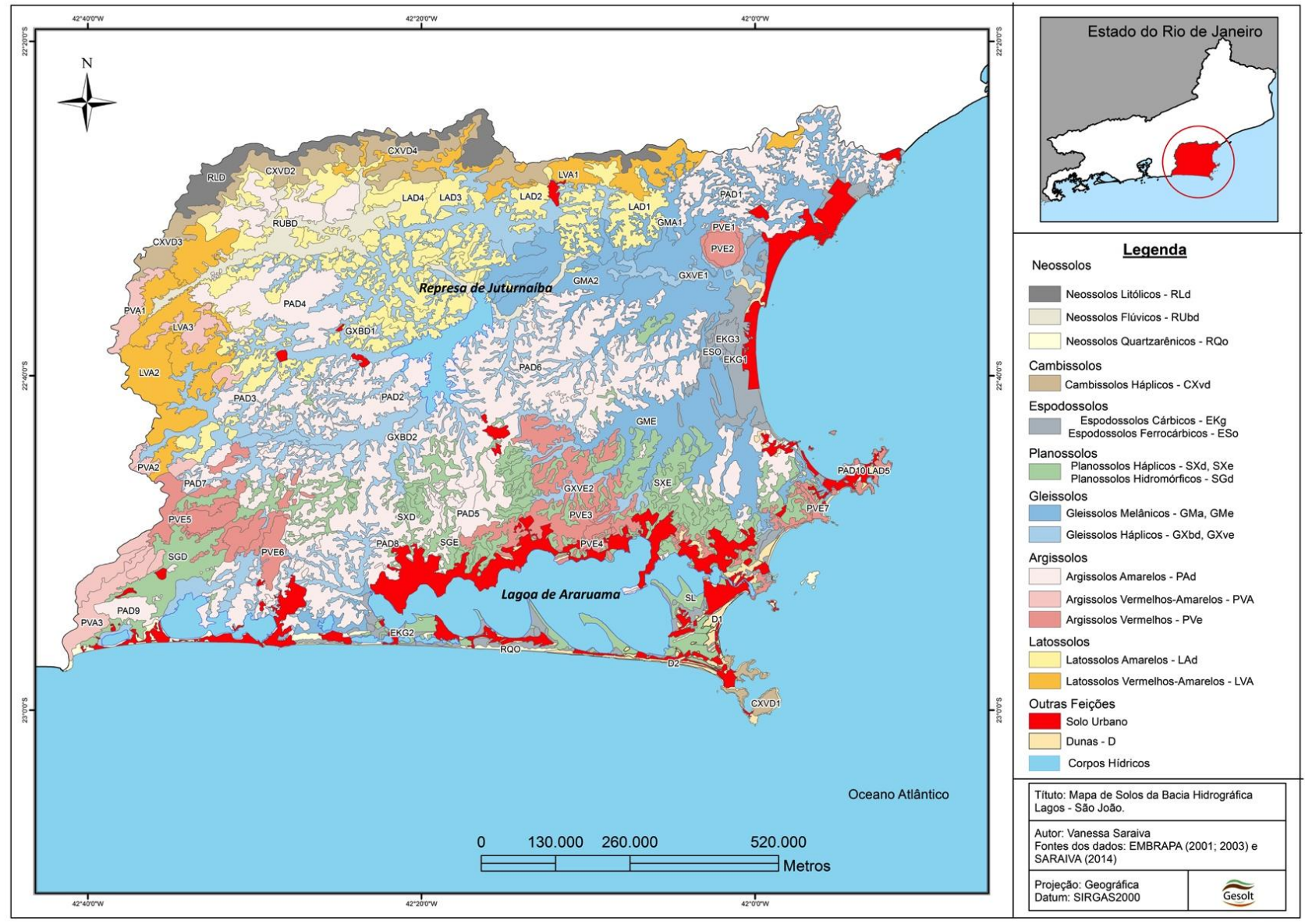

Figura 4. Mapa de solos da bacia do rio São João, Una e Lagos.

\begin{tabular}{|c|llll|}
\hline Sigla & \multicolumn{1}{|c}{ Solo 1 } & Solo 2 & Solo 3 & Solo 4 \\
\hline$\underline{\mathrm{S}}$ & Salinas & & \\
\hline$\underline{\mathrm{D} 2}$ & Duna em processo de revegetação & & \\
\hline$\underline{\mathrm{D} 1}$ & Duna propriamente dita & & \\
\hline$\underline{\mathrm{SGe}}$ & $\begin{array}{c}\text { Planossolo } \\
\text { Hidromórfico }\end{array}$ & Planossolo Háplico & Planossolo Nátrico & Gleissolo Háplico \\
\hline$\underline{\mathrm{SX}}$ & Planossolo Háplico & Planossolo Háplico & $\begin{array}{c}\text { Planossolo } \\
\text { Hidromórfico }\end{array}$ & Argissolo Amarelo \\
\hline$\underline{\mathrm{SGd}}$ & $\begin{array}{c}\text { Planossolo } \\
\text { Hidromórfico }\end{array}$ & Planossolo Háplico & Gleissolo Háplico & \\
\hline$\underline{\mathrm{SXd}}$ & Planossolo Háplico & Argissolo Amarelo & & \\
\hline$\underline{\text { GMa2 }}$ & Gleissolo Melânico & Gleissolo Melânico & & \\
\hline$\underline{\text { GMa1 }}$ & Gleissolo Melânico & Gleissolo Háplico & & \\
\hline
\end{tabular}




\begin{tabular}{|c|c|c|c|c|}
\hline$\underline{\mathrm{GMe}}$ & Gleissolo Melânico & Gleissolo Háplico & Gleissolo Háplico & Gleissolo Háplico \\
\hline GXve2 & Gleissolo Háplico & Planossolo Hidromórfico & & \\
\hline GXve1 & Gleissolo Háplico & Gleissolo Melânico & & \\
\hline GXbd2 & Gleissolo Háplico & Gleissolo Melânico & & \\
\hline$\underline{\text { GXbd } 1}$ & Gleissolo Háplico & Gleissolo Melânico & & \\
\hline$\underline{\text { RUbd }}$ & Neossolo flúvico & Neossolo flúvico & Gleissolo Háplico & \\
\hline$\underline{\mathrm{RQ0}}$ & $\begin{array}{c}\text { Neossolo } \\
\text { Quartzarênico típico }\end{array}$ & $\begin{array}{c}\text { Neossolo Quartzarênico } \\
\text { alico }\end{array}$ & & \\
\hline$\underline{\text { ESo }}$ & $\begin{array}{l}\text { Espodossolo } \\
\text { Ferrocárbico } \\
\end{array}$ & Neossolo Quartzarênico & & \\
\hline$\underline{\text { EKg3 }}$ & Espodossolo Cárbico & Neossolo Quartzarênico & & \\
\hline$\underline{\mathrm{EKg} 2}$ & Espodossolo Cárbico & Neossolo Quartzarênico & & \\
\hline$\underline{\operatorname{EKg} 1}$ & Espodossolo Cárbico & $\begin{array}{l}\text { Espodossolo } \\
\text { Ferrocárbico }\end{array}$ & Neossolo Quartzarênico & \\
\hline$\underline{\mathrm{RLd}}$ & Neossolo Litólico & Cambissolo Háplico & & \\
\hline$\underline{\mathrm{CXvd} 4}$ & Cambissolo Háplico & $\begin{array}{c}\text { Latossolo Vermelho- } \\
\text { Amarelo }\end{array}$ & Latossolo Vermelho & Neossolo Litólico \\
\hline$\underline{\text { CXvd3 }}$ & Cambissolo Háplico & $\begin{array}{c}\text { Latossolo Vermelho- } \\
\text { Amarelo }\end{array}$ & Latossolo Amarelo & Neossolo Litólico \\
\hline$\underline{\text { CXvd2 }}$ & Cambissolo Háplico & $\begin{array}{c}\text { Latossolo Vermelho- } \\
\text { Amarelo }\end{array}$ & Neossolo Litólico & \\
\hline$\underline{\text { CXvd1 }}$ & Cambissolo Háplico & Neossolo Regolítico & & \\
\hline LVA3 & $\begin{array}{c}\text { Latossolo Vermelho- } \\
\text { Amarelo }\end{array}$ & Latossolo Amarelo & $\begin{array}{c}\text { Argissolo Vermelho- } \\
\text { Amarelo }\end{array}$ & \\
\hline$\underline{\mathrm{LVA} 2}$ & $\begin{array}{c}\text { Latossolo Vermelho- } \\
\text { Amarelo }\end{array}$ & Latossolo Amarelo & Cambissolo Háplico & \\
\hline$\underline{\text { LVA1 }}$ & $\begin{array}{c}\text { Latossolo Vermelho- } \\
\text { Amarelo }\end{array}$ & Cambissolo Háplico & Latossolo Amarelo & \\
\hline$\underline{\text { LAd5}}$ & Latossolo Amarelo & Argissolo Amarelo & & \\
\hline$\underline{\mathrm{LAd} 4}$ & Latossolo Amarelo & $\begin{array}{c}\text { Latossolo Vermelho- } \\
\text { Amarelo }\end{array}$ & Argissolo Amarelo & Argissolo Amarelo \\
\hline$\underline{\mathrm{LAd} 3}$ & Latossolo Amarelo & $\begin{array}{c}\text { Latossolo Vermelho- } \\
\text { Amarelo }\end{array}$ & & \\
\hline$\underline{\mathrm{LAd} 2}$ & Latossolo Amarelo & $\begin{array}{c}\text { Latossolo Vermelho- } \\
\text { Amarelo }\end{array}$ & Distrófico & \\
\hline$\underline{\text { LAd1 }}$ & Latossolo Amarelo & $\begin{array}{l}\text { Latossolo Vermelho- } \\
\text { Amarelo argissolico }\end{array}$ & $\begin{array}{l}\text { Argissolo Amarelo } \\
\text { Distrófico latossólico }\end{array}$ & \\
\hline$\underline{\text { PVA3 }}$ & $\begin{array}{c}\text { Argissolo Vermelho- } \\
\text { Amarelo }\end{array}$ & $\begin{array}{c}\text { Argissolo Amarelo } \\
\text { abruptico }\end{array}$ & & \\
\hline$\underline{\text { PVA2 }}$ & $\begin{array}{c}\text { Argissolo Vermelho- } \\
\text { Amarelo }\end{array}$ & Argissolo Amarelo Distró & fico & \\
\hline$\underline{\text { PVA1 }}$ & $\begin{array}{c}\text { Argissolo Vermelho- } \\
\text { Amarelo }\end{array}$ & Argissolo Amarelo & $\begin{array}{c}\text { Latossolo Vermelho- } \\
\text { Amarelo }\end{array}$ & Cambissolo Háplico \\
\hline PVe7 & Argissolo Vermelho & Luvissolo Crômico & Nitossolo Háplico & Neossolo Regolítico \\
\hline
\end{tabular}




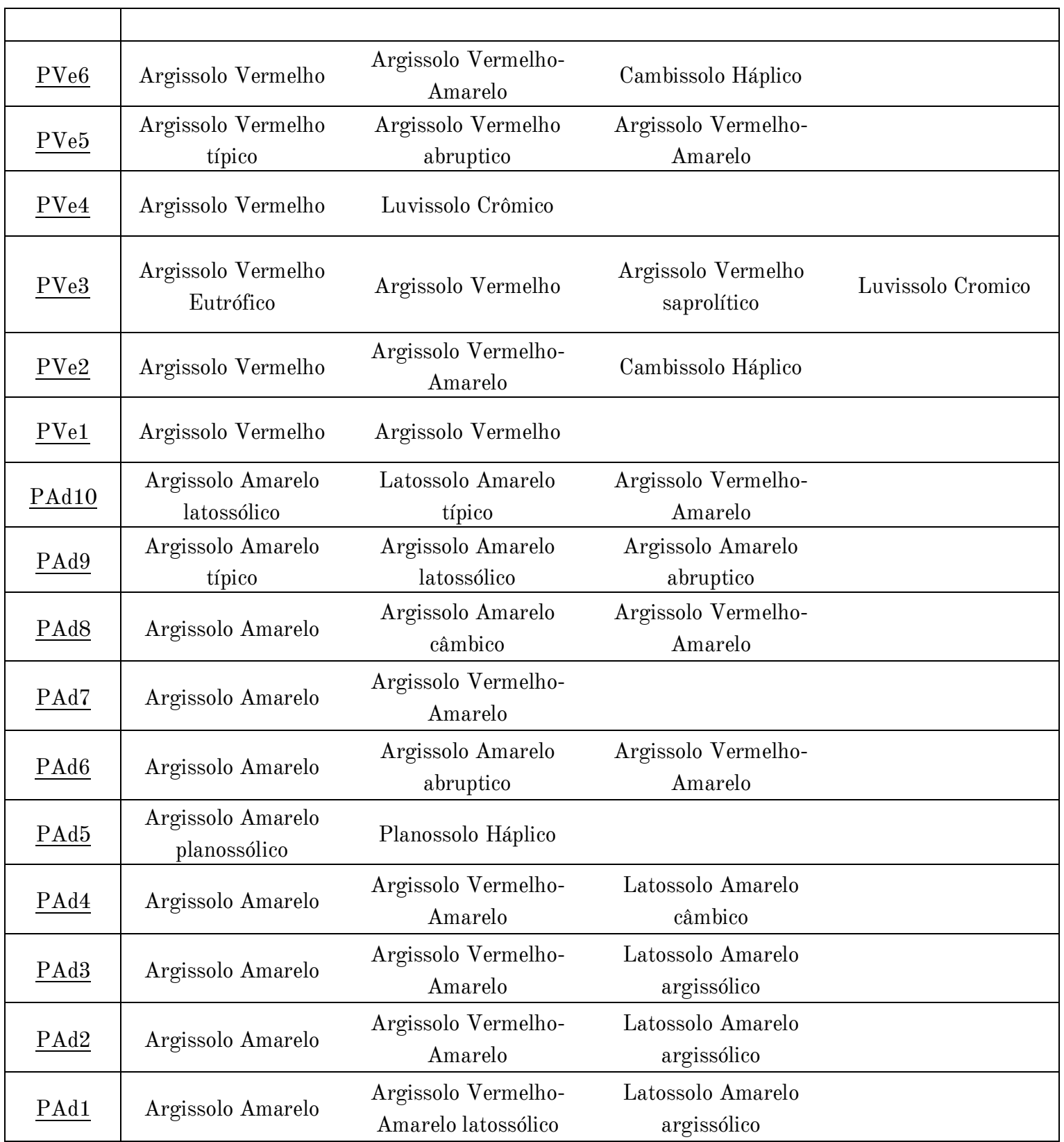

Quadro 2. Classes de solos que compõem as unidades de mapeamento do Mapa de Solos da bacia do rio São João,

Una e Lagos.

Os Argissolos Amarelos, representados pela unidade de mapeamento PAd, compõem a associação de Argissolo mais comum, com uma área equivalente a $868 \mathrm{~km}^{2}$, correspondendo a $25 \%$ do total de solos mapeados dentro da bacia.

As unidades de mapeamento com solos do tipo Latossolo, somam uma área de $532 \mathrm{~km}^{2}$, representando cerca de $15 \%$ da bacia hidrográfica. Os Latossolos Amarelos ocupam uma área de 330 km² (9,3\%). Os Latossolos Vermelho-Amarelos (LVA) ocupam uma área de 202 km² (5,7\%). 
O Neossolo Litólico (RLd) e Cambissolo (CXvd) são solos típicos de áreas de alta declividade e juntas, estas associações somam 5\% dos solos mapeados na bacia. As associações de Cambissolo ocupam uma área de $110 \mathrm{~km}^{2}$. A classe de maior proporção é o Cambissolo Háplico (CXvd4), correspondendo a $48 \%$ da área das unidades de mapeamento formadas por Cambissolos.

As unidades formadas por Gleissolos (GXbd, GXve) ocupam 24\% da bacia, correspondendo a uma área de $855 \mathrm{~km}^{2}$. Estas unidades de solos podem ser encontradas em toda a área da bacia, principalmente nas planícies de inundação da rede de drenagem e áreas inundáveis próximas às diversas lagoas e à represa de Juturnaíba.

Os Planossolos (SGD, SGe, SXe) somam uma área de $292 \mathrm{~km}^{2}$, cerca de $8 \%$ de todos os solos mapeados. As associações com Neossolo Flúvico (RUbd) se estende ao longo das drenagens do rio São João e Una. O Neossolo Quartzarênico (RQo) ocorre junto ao litoral na porção sul da bacia, juntas essas duas unidades somam $91 \mathrm{~km}^{2}$, apenas $2,5 \%$ de todos os solos mapeados na bacia.

Os Espodossolos (ESo e EKg) distribuem-se por todo litoral associado a terrenos arenosos de origem marinha. Estas associações ocupam uma área de $99 \mathrm{~km}^{2}$, cerca de $3 \%$ do total de solos mapeados.

\section{Mapa de Análise Qualitativa da Erosão}

O mapa de suscetibilidade à erosão laminar é apresentado na Figura 5. A classe muito baixa é a predominante na bacia, com cerca de $1.400 \mathrm{~km}^{2}$ (40\%), seguida da classe de alta suscetibilidade, com cerca de $1.120 \mathrm{~km}^{2}(32 \%)$.

Os tipos de solos e tipos de terrenos encontrados na classe muito baixa suscetibilidade são: Espodossolo Cárbico, Espodossolo Ferrocárbico, Gleissolo Melânico, Gleissolo Háplico, Neossolo Quartzarênico, Neossolo Flúvico, Planossolo Hidromórfico, Planossolo Háplico, Planossolo Nátrico, Dunas e Salinas (Quadro 3). 


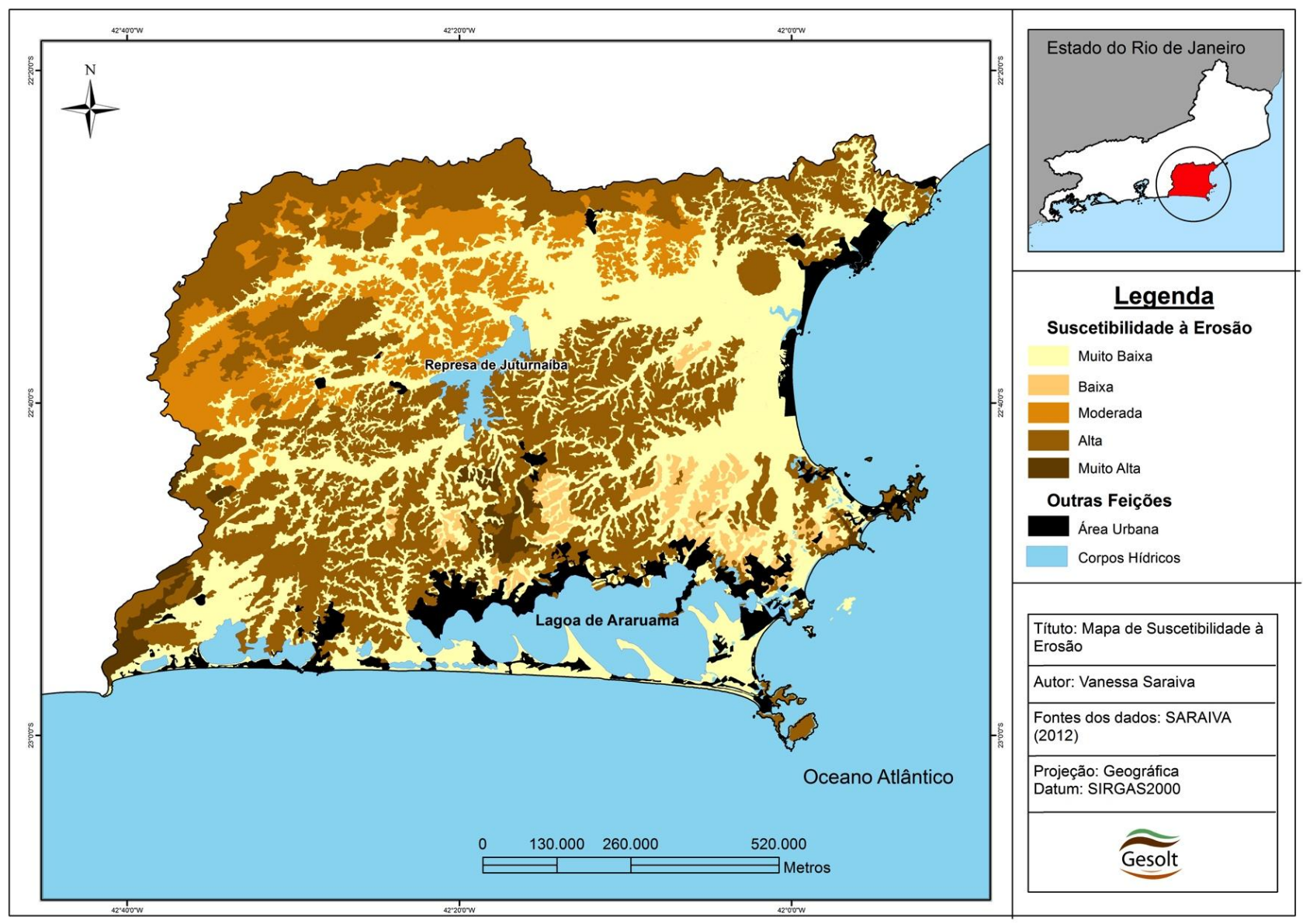

Figura 5. Mapa de suscetibilidade à erosão da bacia do rio São João, Una e Lagos.

Sua distribuição está restrita às planícies e baixadas presentes na bacia. A declividade desta classe varia de 0 a $3 \%$, sendo este, o fator principal para atribuição de uma nota de muito baixa suscetibilidade, visto que nestes relevos não apresentam condições para a geração de um fluxo superficial suficiente para provocar erosão.

\begin{tabular}{|c|c|}
\hline $\begin{array}{c}\text { Classes de Suscetibilidade à } \\
\text { erosão }\end{array}$ & Unidades de Mapeamento \\
\hline Muito Baixa & $\begin{array}{c}\text { SL; D1, D2, SGe, SGd, GMa, GXve, GXbd, RUbd, } \\
\text { RQo, ESo, EKg }\end{array}$ \\
\hline Baixa & SXe, SXd \\
\hline Moderada & LVa2, LVa3, LAd1, LAd2, LAd4, LAd4 \\
\hline Alta & $\begin{array}{r}\text { RLd, CXvd, LVA1, PVA, PVA2, PVe1, PVe2, } \\
\text { PVe3, PVe4, PVe5, PVe6, PAd1, PAd2, PAd3, } \\
\text { PAd4, PAd6, PAd7, PAd8, PAd9, PAd10 }\end{array}$ \\
\hline Muito Alta & LAd5, PVA3, PVe7, PAd5 \\
\hline
\end{tabular}


Quadro 3. Classes de suscetibilidade à erosão dos solos.

A classe de suscetibilidade à erosão baixa apresenta unidades de mapeamento compostas por solos do tipo Planossolo Háplico, Argissolo Amarelo, Gleissolo Háplico, Gleissolo Melânico e Argissolo Amarelo. Esta classe é a que ocupa a menor área espacial, com $137 \mathrm{~km}^{2}$, representando 4\% da área mapeada. Sua ocorrência é pontual, estando associada a trechos onde o relevo é suave ondulado com 3 - $6 \%$ de declividade e uso predominante de campos de vegetação rasteira sem uso comercial.

A classe de suscetibilidade à erosão moderada é formada principalmente por associações de Latossolos, mas ocorre também em Argissolos. As classes de solos encontrados foram o Latossolo Amarelo, Latossolo Vermelho-Amarelo, Latossolo Vermelho e Argissolo Amarelo. Ela representa 11\% de toda área mapeada, ocupando cerca de $390 \mathrm{~km}^{2}$.

Esta classe ocorreu tanto em área de floresta quanto em pastagem, em relevo suave ondulado, ondulado e forte ondulado. 0 tipo de solo foi o principal fator determinante desta classe, pois em áreas de maior declividade a energia para o transporte é maior, porém os Latossolos mostram-se mais resistentes à ação da água do escoamento superficial, pois apresentam boa permeabilidade e drenabilidade conforme destacado por Valle Junior et al. (2009).

Nas áreas da bacia definidas como sendo de alta suscetibilidade à erosão, as unidades de mapeamento são compostas por Argissolo Amarelo, Argissolo Vermelho-Amarelo, Latossolo Amarelo, Latossolo Vermelho-Amarelo, Planossolo Háplico, Luvissolo Crômico, Nitossolo, Cambissolo Háplico, Neossolo Regolítico e Neossolo Litólico (Quadro 3).

À noroeste da bacia, o relevo com declividade acima de 40\% foi o principal fator para atribuição de alta suscetibilidade à erosão. Além disso, destaca-se que as unidades de mapeamento são compostas por associações de Cambissolo, Latossolo, Neossolo Litólico e eventualmente Argissolo, o que contribui para que seja aumentada a suscetibilidade erosiva. Neste trecho da bacia a principal cobertura vegetal 
do solo é do tipo floresta, mas nota-se de forma pontual áreas pastoreio de gado, que geram sinais erosivos severos, na forma de ravinas e voçorocas notados em trabalhos de campo.

Nas áreas nas porções centro-oeste e sudoeste da bacia, o principal fator para a presença da classe de suscetibilidade à erosão alta foi a presença de Argissolos, que possuem fortes descontinuidades texturais e estruturais, e estão situados em relevo constituído morros, morrotes e colinas, com declividade oscilando entre 10 e 30\%. Estas características são suficientes para a deflagração de processos erosivos. Além destes fatores, destaca-se o uso do solo com pastagens o que aumenta ainda mais o risco à erosão (VALLE JUNIOR et al., 2010).

A classe de suscetibilidade à erosão muito alta, ocupa cerca de $425 \mathrm{~km}^{2}$ ou $12 \%$ da área da bacia. Nesta classe ocorreram as associações Latossolo Amarelo e Argissolo Amarelo (LAd5), Argissolo Vermelho-Amarelo e Argissolo Amarelo abrúptico (PVA3), Argissolo Vermelho, Luvissolo Crômico, Nitossolo Háplico e Neossolo Regolítico (PVe7) e Argissolo Amarelo planossólico e Planossolo Háplico (PAd5). Nesta classe, o relevo variou entre suave ondulado a forte ondulado, com tipo de uso de pastagem. Dentre as unidades de mapeamento que compõem a classe muito alta, aquela que apresenta a maior suscetibilidade à erosão é a formada por Argissolo Amarelo planossólico e Planossolo Háplico (PAd5). Além das características dos solos que formam esta unidade, o relevo é ondulado e o uso do solo é com pastagem (Figura 5a). A presença de um Latossolo nesta classe deve-se à sua associação com Argissolos, relevo com elevada declividade e uso de pastagem (Figura 5b).

Esta classe é mais pontual ocorrendo na porção centro-sul da bacia, e também a sudoeste da bacia, onde a declividade é superior a $40 \%$. 

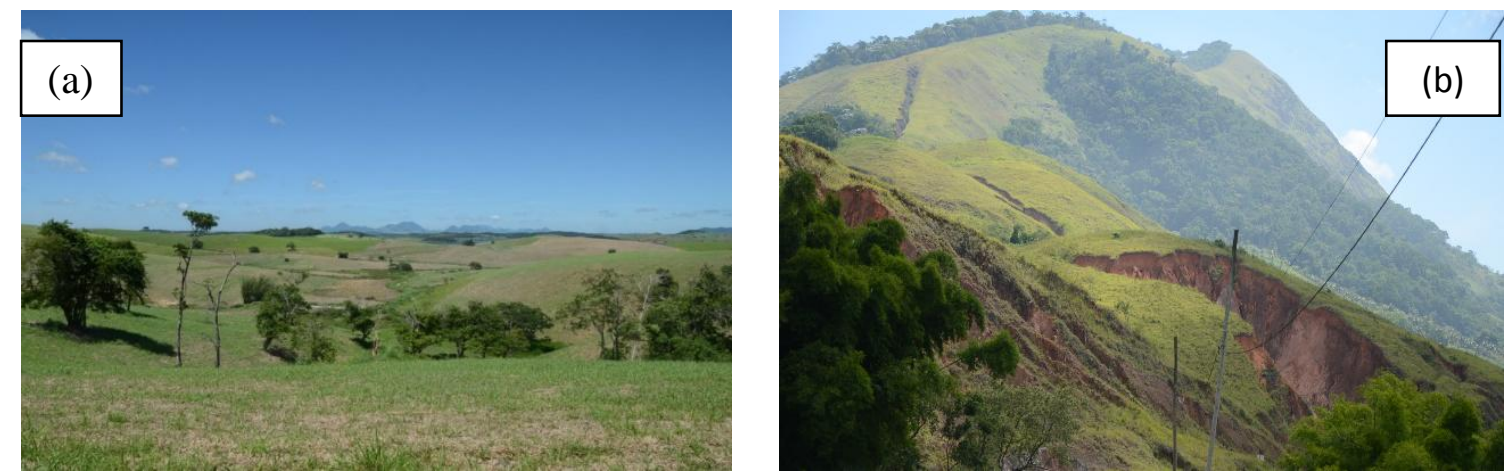

Figura 5. Erosão severa bem distribuída - microbacia do Entorno de Juturnaíba (a); erosão laminar e linear em áreas de Argissolos e Latossolos, alta declividade e uso de Pastagem (b). Fotos: Antonio Soares da Silva (2014).

\section{CONSIDERAÇÕES FINAIS}

A escolha do método Delphi para o auxílio no processo de tomada de decisão foi importante na ponderação das notas para cada classe das características das unidades de mapeamento elencadas para o estudo. Por este processo acontecer pela consulta, e posterior consenso entre especialistas acerca da temática, é possível chegar a uma resposta sólida para as ponderações resultantes deste processo. Foi possível através das notas obtidas avaliar aos fatores que contribuíram para a classificação da susceptibilidade a erosão de cada unidade de mapeamento de solo. Permitindo assim uma visão sistêmica de cada área assim como seus condicionantes.

O mapa de solos mostrou o predomínio dos Argissolos na bacia hidrográfica São João, Lagos e Una. A maior presença destes solos na porção central coincidiu com a ocorrência da classe de suscetibilidade à erosão alta e muito alta, principalmente quando associados com os Planossolos. Este fato decorre das descontinuidades texturais e estruturais que estes solos apresentam.

O relevo teve maior importância na avaliação da suscetibilidade à erosão em dois compartimentos: 1) nos compartimentos montanhosos e escarpados, onde mesmo em áreas cobertas por vegetação a classe de suscetibilidade foi de alta suscetibilidade a erosão laminar, devido a maior declividade; 2) e no compartimento de planícies, que mesmo com solos de alta erodibilidade, devido a textura predominantemente arenosa e uso de pastagem foi classificado como muito baixa e baixa suscetibilidade a erosão laminar, em função da declividade muito baixa. 
As pastagens, que ocupam quase toda a área de estudo, quando associadas as áreas com solos mais suscetíveis a erosão laminar geraram, de acordo com o modelo, regiões de alta e muito alta suscetibilidade à erosão. 0 pisoteio do gado aliado a falta de programas de manejo e conservação de solos aceleram o processo erosivo.

As áreas de relevo montanhoso e escarpado estão, em grande parte, recobertas por florestas, o que diminui a probabilidade da incidência erosão laminar. No entanto, outros processos de remoção dos solos podem ocorrer, tais como, os movimentos de massa.

A importância de mapas de suscetibilidade se traduz pelo fornecimento de subsídios para comitês de bacia e prefeituras para auxiliar na elaboração de planos de manejo e mecanismos de planificação do uso de solo, bem como, na adoção de medidas para mitigar e evitar a erosão acelerada destes solos, evitando assim o maior assoreamento dos corpos hídricos.

\section{REFERÊNCIAS}

ADLER, Michael; ZIGLIO, Erio. Gazing into the oracle: the Delphi Method and its Application to Social policy and Public Health. 1 ed. Bristol: Jessica Kingsley Publishers. 1996. 252p.

BERTONI, José; LOMBARDI NETO, Francisco. Conservação do Solo. 1 ed. São Paulo: Editora Ícone, 1990. 216p.

BESKOW, Samuel; MELLO, Carlos Rogério; NORTON, Lloyd Darrel; CURI, Nilton; VIOLA, Marcelo Ribeiro; AVANZI, Junior César. Soil erosion prediction in the Grande River Basin, Brasil using distributed modeling. Catena, Amsterdam. v.79. n.1. p. 49-59. outubro.2009.

BILOSLAVO, Roberto; GRENBENC, Andrej. Integreting group Delphi, analytic hierarchy process and dynamic fuzzy cognitive maps for a climate warning scenario. Regular Journal Paper, Nova Jersey v.41, n.3/4, p. 414-428. abril.2012.

BOARDMAN, John; POESEN, Jean. Soil erosion in Europe: major processes, causes and consequences. In: BOARDMAN, John; POESEN, Jean. Soil Erosion in Europe. 1 ed. Chinchester: John Wiley e Sons Ltd. 2006. 878p. p. 478-487.

BRYANT, Derek. L.; ABKOWITZ Mark. D. Development of a Terrestrial Chemical Spill Management System. Journal of Hazardous Materials. Nova Iorque v.147. n. 1. p. 78-90. agosto. 2007.

CARVALHO FILHO, Amaury; LUMBRERAS, José Francisco; WITTERN, Klaus Peter. Mapa de reconhecimento de baixa intensidade dos solos do estado do Rio de Janeiro. Boletim de Pesquisa e Desenvolvimento. Rio de Janeiro: Embrapa Solos. 2003. 245p.

CUNHA, Sandra Baptista da. Impactos das obras de engenharia sobre o ambiente biofísico da bacia do Rio São João (Rio de Janeiro - Brasil). 1 ed. Rio de Janeiro: Editora Instituto de Geociências, 1995. 378p. 
CUNHA, Sandra Baptista da; FREITAS, Marcos Welausen Dias de. Geossistemas e Gestão Ambiental na Bacia Hidrográfica do Rio São João - RJ. GEOgraphia. Rio de Janeiro v.6, n.12, p. 87-110. jan. 2004.

EMPRESA BRASILEIRA DE PESQUISA AGROPECUÁRIA. Manual de métodos de análise de solos. 2. Ed. Rio de Janeiro: EMBRAPA. 1997. 212p.

EMPRESA BRASILEIRA DE PESQUISA AGROPECUÁRIA. Sistema brasileiro de classificação de solos. 3.ed. Brasília: EMBRAPA. 2013. 353p

GUERRA, Antonio José Teixeira., FULlEN, Michael. A. ; JORGE, Maria do Carmo Oliveira; ALEXANDRE, Silvia Teixeira. Soil Erosion and Conservation in Brazil. Anuário do Instituto de Geociências (UFRJ. Impresso). Rio de Janeiro v. 37. n. 1. p. 81-91, 2014.

GUERRA, Antonio José Teixeira. Degradação dos Solos - Conceitos e Temas. In: GUERRA, A.J.T.; JORGE, Maria do Carmo Oliveira. Degradação dos Solos no Brasil. 1. ed. Rio de Janeiro: Bertrand Brasil. 2014. 317p. p.16-42.

Instituto Brasileiro de Geografia e Estatística. Manual Técnico de Pedologia. 2.ed. Rio de Janeiro: IBGE. 2007. 315p.

JORGE, Maria do Carmo Oliveira; GUERRA, Antonio José Teixeira. Erosão dos solos e movimentos de massa - recuperação de áreas degradadas com técnicas de bioengenharia e prevenção de acidentes. In: GUERRA, Antonio José Teixeira; JORGE, Maria do Carmo Oliveira. Processos erosivos e recuperação de áreas degradadas. SãoPaulo: Editora Oficina de Textos. 2013. 192p. p. 7-30.

LEMOS, Raimundo Costa de.; SANTOS, Raphael David dos. Manual de descrição e coleta de solo no campo. Sociedade Brasileira de Ciência do Solo. 3 ed. Campinas: Centro Nacional de Pesquisa de Solos. 1996. 83p.

LUMBRERAS, José Francisco; CARVALHO FILHO, Amauri; CALDERANO FILHO, Braz; SANTOS, Rafael David. Levantamento pedológico, vulnerabilidade e potencialidade ao uso das terras - Quadrículas de Silva Jardim e Rio das Ostras. Rio de Janeiro: Embrapa Solos. Boletim de Pesquisa, n. 23, 221p. 2001.

LUO, Shilong; WANG, Houjie; FENG, Cai. An integrated risk assessment of coastal erosion based on fuzzy set theory along Fujian coast, southeast China. Ocean \& Coastal Management, v.84. n1 p. 68-76. ago. 2013.

MARINO, Tiago Badre; SILVA, Jorge Xavier; QUINTANILHA, José Alberto. Metodologia para tomada de decisão no âmbito de riscos socioambientais em áreas urbanas: Desmoronamento e enchentes em assentamentos precários na bacia do córrego Cabuçu de Baixo - SP. Revista Brasileira de Cartografia. Rio de Janeiro v.64, n.1, p. 83-101. jan. 2012.

MARTÍN-FERNÁNDEZ, Luis; MARTÍNEZ-NÚÑEZ, Margarita. An empirical approach to estimate soil erosion risk in Spain. Science of The Total Environment. Barcelona v. 409, n. 17, p. 3114-3123. ago. 2011.

MORGAN, Roy. Soil Erosion and Conservation. 3 ed. Oxford: Blackwell Publishing. 2005. 686p.

MUNSELL COLOR COMPANY. Munsell Soil Color Charts. Baltimore:1994. 97p.

ROSSI, Marcio; PFEIFER, Rui Marconi. Remoção de material erodido dos solos de pequenas bacias hidrográficas no Parque Estadual da Serra do Mar em Cubatão (SP). Bragantia (online). Campinas, v.58, n.1, p. 141-156. fev. 1999.

SHI, X.Z.; WANG, K.; WARNER, E.D.; YU, D.S.; WANG, H.J.; YANG, R.W.; LIANG, Y.; SHI, D.M. Relationship between soil erosion and distance to roadways in undeveloped areas of China. Catena. Amsterdam. v.72. n.2. p. 305-313. jan. 2008. 
VALE JUNIOR, José Frutuoso do; BARROS, Luciana da Silva; SOUSA, Maria Ivonilde Leitão de; UCHÔA, Sandra Catia Pereira. Erodibilidade e suscetibilidade à erosão dos solos de cerrado com plantio de Acacia mangium em Roraima.

Agroambiente (online). Boa Vista. v.3, n.1, p. 1-8. jan-jul. 2009.

VALLE JUNIOR, Renato F. do; GALBIATTI, João A.; MARTINS FILHO, Marcílio V.; PISSARRA, Teresa C.T. Potencial de erosão da bacia do rio Uberaba. Engenharia Agrícola. Jaboticabal. v.30, n.5, p. 808-908. set/out. 2010.

VITTE, Antonio Carlos; MELLO, Juliano Pereira de. Considerações sobre a erodibilidade dos solos e a erosividade das chuvas e suas consequências na morfogênese das vertentes: um balanço bibliográfico. CLIMEP - Climatologia e Estudos da Paisagem. Rio Claro. v.2, n.2, p. 107-133. jul/dez. 2007.

WANG, K.; WANG, H.J.; SHI, X.Z.; WEINDORF, D.C.; YU, D.S.; LIANG, Y.; SHI, D.M. Landscape analysis of dynamic soil erosion in subtropical China: A case study in Xingguo Country, Jiangxi Province. Soil \& Tillage Research. South Carolina. v.105, n.2, p. 313-321. nov. 2009. 